\title{
Patterns of scaffolding in computer-mediated collaborative inquiry
}

\author{
Lakkala, Minna
}

2005

Lakkala , M , Muukkonen , H \& Hakkarainen , K 2005 , ' Patterns of scaffolding in computer-mediated collaborative inquiry ', Mentoring \& Tutoring, vol. 13 , no. 2 , pp. 281-300 . https://doi.org/10.1080/13611260500107457

http://hdl.handle.net/10138/27955

https://doi.org/10.1080/13611260500107457

submittedVersion

Downloaded from Helda, University of Helsinki institutional repository.

This is an electronic reprint of the original article.

This reprint may differ from the original in pagination and typographic detail.

Please cite the original version. 
Patterns of scaffolding in computer-mediated collaborative inquiry

Minna Lakkala, Hanni Muukkonen \& Kai Hakkarainen

Centre for Research on Networked Learning and Knowledge Building, Department of

Psychology, P.O. Box 9, 00014, University of Helsinki, Finland.

\section{Minna Lakkala}

E-mail: minna.lakkala@helsinki.fi

Tel.: +358 (9) 8057023

GSM: +358 (40) 7254889

Fax: +358 (9) 8594596

Hanni Muukkonen

E-mail: hanni.muukkonen@helsinki.fi

Tel.: +358 (9) 19129476

GSM: +358 (50) 3306236

Fax: +358 (9) 19129443

Kai Hakkarainen

E-mail: kai.hakkarainen@helsinki.fi

Tel.: +358 (9) 7263952

GSM: +358 (50) 4129572

Fax: +358 (9) 19129443

Contact person:

Minna Lakkala

Centre for Research on Networked Learning and Knowledge Building

Department of Psychology

P.O. Box 9

00014 University of Helsinki, Finland

E-mail: minna.lakkala@helsinki.fi

Tel.: +358 (9) 8057023

GSM: +358 (40) 7254889

REVISED: February 15, 2005 


\begin{abstract}
There is wide agreement on the importance of scaffolding for student learning. Yet, models of individual and face-to-face scaffolding are not necessarily applicable to educational settings in which a group of learners is pursuing a process of inquiry mediated by technology. The scaffolding needed for such a process may be examined from three perspectives: the organisation of activities, the affordances of tools, and process-level guidance. The purpose of the present study was to assess three tutors' contributions to university students' computermediated discourse organised as a question-driven inquiry process. In all, 17 students participated in the discourse as part of their studies in a cognitive psychology course. Quantitative and qualitative analyses were conducted to investigate critical patterns and possible effects of the tutors' process-level scaffolding. During the process, the more experienced tutors acted as metalevel commentators, whereas the less-experienced tutor participated in the inquiry as a co-inquirer who also produced inquiry questions. More elaborate scaffolding to foster students' metacognitive awareness of the inquiry strategies was generally lacking in all three tutors' data. Implications for pedagogical improvement in collaborative, computer-supported educational settings are discussed.
\end{abstract}




\section{Introduction}

The possibilities and challenges of computer-supported collaborative learning (CSCL) have been intensively investigated in recent educational research (Dillenbourg, 1999; Koschmann, Hall \& Miyake, 2001; Lehtinen, 2003). The CSCL approach is built on social constructivist and sociocultural perspectives of learning, and it can be defined as a pedagogical approach in which participants collaborate through the computer in a learning situation, supported by several network-based collaboration tools (Lehtinen, 2003). According to many studies, advanced collaborative technology can be beneficial for students' learning, but it does not by itself guarantee successful results; appropriate pedagogical arrangements and guidance during the collaborative learning endeavour are also required (Dysthe, 2000; Hara, Bonk \& Angeli, 2000). Most studies on CSCL have, however, concentrated on students' activity; the instructor or tutor's role has been investigated less often.

Puntambekar and Kolodner (1998) argued that, in complex learning environments, support for learners should be distributed across the various agents that play a role in a learning process. Probably the most effective approach is an integration of various modes of supportboth those embedded in the pedagogical approach, tasks, and tools, as well as those manifested in the human tutors' situation-specific guidance. With reinforcement from the literature, we suggest three complementary pedagogical levels to be addressed when discussing support for students in CSCL settings:

1. The task organisation level, which means the initial "framing" or organising of the learning group's activities, or structuring the task according to the chosen pedagogical approach (Bielaczyc, 2001; Wells, 2000);

2. The tool level, which means built-in structures or software tools in the educational technology environments for structuring and directing students’ work (Reiser, 2004); 
3. The process level, which involves human coaching, situation-specific guidance, and expert participation during the collaborative activity (Rourke, Garrison \& Archer, 2001). The present study concentrates on this third level while recognising that the levels are intertwined.

According to a number of researchers (Edelson, Gordin \& Pea, 1999; Hakkarainen \& Sintonen, 2002; Scardamalia \& Bereiter, 1994), organising the collaborative process as question-driven inquiry provides methods for facilitating students' learning and knowledge building efforts in CSCL. In practice, institutional and curricular constraints often diminish the possibilities of arranging university courses mainly according to high-level inquiry principles. For instance, in the Finnish higher education system, university courses are usually arranged as parallel, semester-long courses run by one instructor, with two lectures each week, and a final exam in the end; thus students' questioning has hardly any influence on course content or direction. Therefore, it would also be desirable to find ways to enrich existing educational practices by bringing in elements of higher-order inquiry into traditional lecture courses.

Background and context

In an earlier study (Muukkonen, Hakkarainen \& Lakkala, 1999), we investigated undergraduate students' engagement in a cognitive psychology course in which lecturing was supplemented, between the lectures, by computer-mediated collaboration. Collaboration was organised as question-driven inquiry discourse, and 13 undergraduate students from a Finnish university were provided with web-based asynchronous software that included built-in scaffolds to support collaborative inquiry. The study results provided evidence that the pedagogical arrangements and the tools used stimulated the students to produce questions and elaborate explanations about the topic. Yet the discourse was not very deep; elaboration of students' own explanations into more theoretical explanations was only weakly evident in their work.

In a subsequent study (Muukkonen, Lakkala \& Hakkarainen, 2001), the present researchers analysed students' engagement in a similar lecture course in which there were also tutors participating in the students' computer-mediated inquiry discourse between the lectures. 
In this course, the general pattern of all the students' knowledge productions was very similar to the previous course: The students produced many problems and, especially, their own explanations for the problems, but not as many elaborated scientific explanations as were expected. There was, nevertheless, some variation in separate groups' knowledge productions, which provoked our interest in analysing the tutors' activity in the course. Three separate groups, including the tutors, took part in the course, which provided an opportunity to examine the influences of the tutors' process level scaffolding, since the organisation of activity and tools were the same for all groups. We will begin by providing a background for the research through an examination of earlier studies of scaffolding and tutoring.

From individual scaffolding to tutoring virtual communities of inquiry

As Brown, Ash, Rutherford, Nakagawa, Gordon and Campione (1993) stated in the context of discovery learning, tutors should take the difficult role of being in the middle ground of guided inquiry learning. They should not rely too much on students' spontaneous inquiry and should intervene if students are not able to make progress on their own. On the other hand, too much control prevents students' self-directed learning activity and restricts their cognitive efforts. These challenges can be related to choices that must be made during process guidance. Questions to be asked include, for instance, whether the tutor should take an active role as an expert model in contributing to the process, or allow the students to work as much as possible for themselves. Also, how do tutors give guidance that helps the learners assume responsibility for cognitively more challenging tasks in the inquiry?

The concept of scaffolding was developed in order to define what kind of help should be given to a learner and was first introduced by Wood, Bruner, and Ross (1976) in their investigation of an adult helping a learner in a task that is too difficult. According to them, scaffolding included such elements as arousing the learner's interest in the task; reducing the complexity of problem to suit the learner's level of expertise; directing the learner's activity towards the task goals; highlighting the critical features of the task; and modelling the solution 
to a task. Most subsequent studies of scaffolding or successful expert tutoring (e.g., Lepper, Drake \& O`Donnell-Johnson, 1997; Wood \& Wood, 1996) were based on individual tutoring situations. Yet, Kolodner (2001) stated, models of individual scaffolding are not necessarily applicable to educational settings in which a group of learners is pursuing a common goal.

Another common feature of the above studies of scaffolding and tutoring is that the tasks that the learners faced were rather formal, structured problems that had known, correct solutions. In instructional settings following question-driven inquiry, by contrast, the problems are often open-ended; students are treated as experts who have knowledge to share, and they are encouraged to create (what is for them) new explanations (Hakkarainen, 2003; Scardamalia \& Bereiter, 1994). In such an approach, the purpose is to promote students' cognitive advancement and metacognitive awareness, with support given only when necessary, in order to coach the students gradually to take up responsibility for higher-order aspects of learning (Bereiter \& Scardamalia, 1987; Hogan \& Pressley, 1997; Ligorio, Talamo \& Simons, 2002).

In addition, if the communication is mediated by technology, it further changes what is appropriate in scaffolding and tutoring. Tutors have to learn new ways to support students' work 'virtually', through asynchronous or synchronous communication channels, compared to more familiar ways in face-to-face contact (Lakkala, Ilomäki, Lallimo \& Hakkarainen, 2002; Ligorio et al., 2002; Russell \& Perris; 2003). Previous studies and models of teachers' or tutors' contributions to group learning or collaborative inquiry were based on face-to-face group instruction or classroom settings (Levin, 1999; Mercer \& Fisher, 1993).

The teacher is very often at the centre of discussions in traditional classrooms, and collaborative technology does not necessarily, by itself, change the situation for the better. Guzdial (1997) reported findings about the teachers' and the tutors' dominant roles in college courses in which a CSCL forum was used. In eight courses out of ten, it was the teacher or teaching assistant who produced the highest number of notes; also, the second most productive writer was the teaching assistant in three of the ten courses. Lahti, Seitamaa-Hakkarainen, and 
Hakkarainen (2003) found that the teacher mediated a great deal of interaction between the students in a university-level design course following progressive inquiry. This finding addressed the teacher's cognitive centrality, which refers to a person's crucial role in sharing knowledge with other members of a group, and thus relates to a person's social status (Stasser, 1999); Lahti and her colleagues raised questions about the inquiry-hindering effects of such centrality.

\section{Purpose and scope of the study}

The focus of the present study is on the tutors' contribution to students' computermediated collaborative inquiry. The setting was a 4-month, undergraduate university course in cognitive psychology, in which students pursued collaborative inquiry in three separate groups, using a web-based groupware system between weekly lectures, with the support of a tutor participating in each group.

The organisation level scaffolding was provided by structuring the computer-mediated activity following the ideas of progressive inquiry, a pedagogical framework developed by Hakkarainen and his colleagues (Hakkarainen, 2003; Muukkonen, Hakkarainen \& Lakkala, 2004) for facilitating knowledge-building practices in educational settings. The progressive inquiry model posits that students' genuine questions and previous knowledge of phenomena are a starting point of a deepening process, in which students explain phenomena, share their expertise and build new knowledge collaboratively with the support of technology and knowledge sources. The progressive inquiry framework is based on theories of knowledge building (Scardamalia \& Bereiter, 1994), an interrogative model of scientific inquiry (Hintikka, 1982), and concepts of distributed expertise (Brown et al., 1993).

The role of the instructor in the investigated course was a pedagogical organiser and content knowledge expert; he gave the weekly lectures, as in a typical undergraduate university course, but did not participate in the computer-mediated activity. The process-level scaffolding for the students was arranged by providing each student group with a tutor. The tutors were 
post-graduate students in educational psychology with good skills in using information and communication technologies (ICT) but varying expertise in teaching. Their role was to keep the discourse active, deepening, and focused on the generated research questions. They were also expected to encourage the students to build on each other's ideas and to plan, monitor, and evaluate the inquiry process themselves.

The questions addressed in the present study are the following: 1) How do the tutors participate in university students' computer-mediated progressive inquiry discourse; 2) How does the nature of the tutors' scaffolding influence the students' engagement in inquiry; and 3) What recommendations might be appropriate, based on the results, to develop models and practices for scaffolding computer-mediated collaborative inquiry?

\section{Research methodology}

\section{Course setting}

The investigated course was a 15-week, undergraduate university course, Psychology of Learning and Thinking II. It yielded two-credits to complete a ten-credit minor unit in psychology offered to degree students at the University of Helsinki. The course consisted of weekly 2-hour lectures and tasks between the lectures. Eighty students took part in a course, but they were divided in two conditions; 17 of them chose to use the Future Learning Environment (FLE) between lectures for collaborative inquiry. This study is based on an analysis of these 17 students' and the three tutors' written postings to FLE's common database. The rest of the students were in the other condition; they did not use any groupware, but participated in the course in a more traditional format, following lectures and writing learning logs. Comparison of all students' knowledge productions in the two conditions has been reported in another study (Muukkonen et al., 2001).

The tool used in the investigated course, Future Learning Environment (FLE), is an asynchronous groupware system designed for supporting knowledge building and progressive inquiry in educational settings (see http://fle.uiah.fi). FLE is an Open Source and Free Software, 
and its development is continuing (see http://fle3.uiah.fi). The Knowledge Building module provides threaded discourse forums for working together to solve problems and develop common ideas. In the investigated course, a new forum was founded for each problem formulated in the first lectures, and the students were guided to continue the discourse by writing more specific problems, explanations and scientific knowledge under each problem. The notes were visible to all members in the same study group. In the discourse forums, each note had to be categorised by choosing a scaffold label corresponding to the progressive inquiry elements (Problem, Working theory, Deepening knowledge, Comment, Metacomment, or Summary); similar categories had been employed in Computer-Supported Intentional Learning Environment (CSILE; see Scardamalia and Bereiter, 1994). The system also provided each participant with a Virtual WebTop for storing and sharing documents. During the investigated course, the WebTops were used to share study materials, articles and editable documents; the contents of these documents are not analysed in the present study.

As already mentioned, the course was enriched by the elements of progressive inquiry. During the first two lectures, all the students were guided to formulate research problems. Initially, they produced the research problems individually, continued by discussing their problems with a peer, and then engaged with a small group. Each group presented the most interesting questions to all the participants in the lecture, e.g., "What is intelligence and how can it be measured?" Finally, the teacher grouped the questions together in three lists, consisting of 3-4 questions, to be further studied in FLE course in three groups. The students themselves chose the questions to investigate (and hence the group in FLE). The groups consisted of four to seven students. The requirement for course credit was to contribute actively to the progressive inquiry process in FLE by writing one's own questions and explanations, and by commenting on the productions of the other group members. Information sources used were the weekly lectures and scientific articles distributed by the teacher. At the end of the course, the students were also expected to write a summary of their own contributions and learning process. 
We provided each group with a tutor participating in their FLE-work, as the chosen means of scaffolding the inquiry process. The tutors were acquainted with the principles and goals of progressive inquiry, but they did not receive any explicit or specific guidance about the ways that they might contribute to the FLE discourse. The tutors did not meet the students in person during the course. The teacher in the course, who gave the lectures, sent one starting note to each FLE group (including general instructions for working), but did not otherwise participate in the FLE-work.

The teacher's contribution to sharing theoretical and scientific information to the students was crucial. The students had lively conversations with the teacher during the lectures, but these were not recorded or documented in the study.

\section{Participating students and tutors}

The students in the course were undergraduate students from many fields of study at the University of Helsinki, including forensics, mathematics, history, languages, and education. They took part in this two-credit course to complete a ten-credit minor unit in psychology. They had a previous course, Psychology of Learning and Thinking I, before enrolling for this course. The mean grade (on a three point scale, with 3 being the highest) from the prior course for the 17 members of the FLE groups was $1.8(\mathrm{SD}=.72)$. There was no statistical difference in the mean grades of the other students in the same course $(\mathrm{M}=1.9, \mathrm{SD}=.68)$; therefore, we concluded that the students in the FLE-groups were not exceptional students in that sense. The age of the 17 students varied from 21 to 30, with a mean of 24 years. Year in studies varied from 0 to 6 years, the average being 3 years. The majority of students taking part in the course were females, which was also reflected in the gender distribution of the investigated FLE groups: 5 males and 12 females.

The three tutors were post-graduate psychology students, all females, who were members of the research group conducting the present research. The tutors were of ages 30 (Tutor 1), 39 (Tutor 2) and 26 (Tutor 3) years old. Tutors 1 and 2 were competent in using ICT 
and had substantial teaching experience as lecturers in adult education. They also knew the theoretical basis of progressive inquiry very well, and Tutor 1 had participated in the design work of FLE, but they had not previously participated in tutoring a progressive inquiry process. The youngest tutor was familiar with computers and the basics of cognitive psychology and progressive inquiry, but she did not have earlier teaching or tutoring experience; she was a newcomer in the research group.

\section{Data collection and analysis}

The material produced by the three study groups to FLE's discourse forums constituted the data analysed in the study. The material was retrieved for analysis so that all the posted notes were arranged in hierarchical order based on the reply structure; the first notes of each thread were listed in chronological order. The course was in Finnish; therefore, all the text examples presented in the present article have been translated into English. Table I is a summary of the data used.

\section{--Insert Table I here--}

Descriptive statistics of the groups' discourse engagement. To get an overview of the variation in the study groups' discourse engagement, several measures were computed from each group's data: the number of the postings, the number of starting notes and reply notes, and the usage of inquiry scaffolds. An examination of the content of the notes indicated that they usually consisted of several ideas. In order to analyse the richness of the produced knowledge, the notes were segmented into propositions, each of which was considered to represent a separate idea. To analyse the reliability of the segmentation, an independent coder classified, similarly, approximately $5 \%$ of all notes into segments. The inter-coder reliability (single measure intraclass correlation; see McGraw \& Wong, 1996) was .88, indicating that the reliability of segmentation was satisfactory. The teacher's three starting notes (including general instructions for working) were not included in the analyses. 
Analysis of the content of the tutors' scaffolding. In order to get an overview of the tutors' scaffolding, the content of the tutors' notes was analysed, in detail, by methods of qualitative content analysis (see Chi, 1997). The same segmentation of note texts into ideas was used as in the earlier analysis, and each segment was categorised according to the object of scaffolding it represented. The categories were derived from several preliminary analyses of the tutors' notes; the following four categories were used in the final classification:

1. Ask explanation-seeking question: Ideas assigned to this category were research questions into the inquiry process, questions about refocusing the discussion or questions directed explicitly to students to elaborate their explanations.

2. Produce expert's explanation: Ideas in this category represented the tutors' own explanations of the problems discussed, or references to scientific explanations or theories.

3. Review and evaluate the discourse: Ideas assigned to this category included summaries or reviews of the discourse, references to students' contribution, positive and supportive evaluation, or unmodified quotations from students' texts.

4. Recommend study practices: Ideas assigned to this category represented instructions for working in the course or in the inquiry process, and technical advice about FLE.

In the content analysis, each segment or idea in the tutors' notes was classified to one of these four scaffolding categories. All of the ideas fitted into these four categories of ideas, which were set up as mutually exclusive. To analyse the inter-coder agreement of the categorisation, an independent coder classified approximately $40 \%$ of ideas in the tutors' notes. The coefficient for coder agreement (Cohen's Kappa) was .89, which is indicative of a clearly stronger congruity than chance alone would produce.

Analysis of the discourse progression. In the third phase of data analysis, more exploratory methods were used to evaluate the possible influence of the tutors' scaffolding practices on the students' engagement in inquiry. For this purpose, the unit of analysis was extended to cover the entire material for each group to enable a process perspective on the 
discourse. Two researchers read the data several times and formed their individual opinions of it. After that, characteristic differences were jointly identified through discussions between the researchers. Consequently, the process analysis presents a synthesis of what were considered as the most influential features in the process-level scaffolding in the three groups.

Results

\section{Descriptive statistics of the groups' discourse engagement}

The variation in the three study groups' discourse engagement was examined, first, by counting some descriptive parameters of the discourse data. The students posted 203 notes, 11.9 notes per student on average (minimum was 3, maximum 33 notes), to FLE's database during the course. The tutors posted 35 notes, 11.7 notes per tutor on average. Regardless of the low activity of some students in FLE, all students participated in the entire course and received a final credit.

Most of the produced notes were rather long, and they included many elements of inquiry. As previously described, all the text in the notes was segmented into ideas. The students' 203 notes included 1353 ideas, 6.7 ideas per note on average. The tutors' 35 notes consisted of 159 ideas, 4.5 ideas per note on average. Table II, as an example, displays the four first notes of a discourse thread of six notes, concerning the problem "What is the meaning of motivation in relation to studying?" in Group 3. The general style of the discourse in all the three study groups resembled this kind of topic-centred conversational style manifested in the example.

--Insert Table II about here--

To represent the content of notes, the software prompted and scaffolded the students, providing a choice of labels they were to use for each note posted to FLE's discourse forums. The tutors used the label, Metacomment, in $43 \%(\mathrm{~N}=15)$ of their notes, which indicates that they themselves considered their role to be metalevel process organisers and evaluators rather than equal participants in the process. Another frequently used label in the tutors' notes was 
Comment, 29\% ( $\mathrm{N}=10)$. The students classified $55 \%(\mathrm{~N}=111)$ of their notes as Comments, and only $6 \%(\mathrm{~N}=13)$ as Metacomments.

In all forums together, there were 83 top-level notes (34\% of all notes), which were treated as new initiations in the discourse. Of those notes, 40 (48\%) were isolated notes that did not have any reply notes following, and $43(52 \%)$ were notes that had at least one reply note; e.g., they had started a new discourse thread. Mean number of notes in the discourse threads (including at least two notes) was $4.65(\mathrm{SD}=3.89)$. The shortest threads included two notes; the longest included 20 notes. We wanted, especially, to evaluate the tutors' centrality in their study groups; e.g., whether they acted more like active initiators of new discourse openings, or rather reacted to the students' notes. In Table III are presented the characteristics of the threads, posted notes, and replies in each group.

--Insert Table III about here--

The analysis of the students' activity measures in Table III indicates that the discourse engagement differed, especially, in Group 3 compared to Groups 1 and 2. The notes in Group 3 appear to be, on average, shorter (fewer ideas per note); the students produced more notes, and the discourse threads were longer than in Groups 1 and 2. Also the replying to others' notes was more active in Group 3. Based on these results, some evidence has been found suggesting that the discourse in Group 3 may have been more dialogic than in groups 1 and 2 .

There were substantial differences also among the three tutors in their participation patterns. None of the tutors was the most active participant in her group. A large majority (89\%) of the notes sent by Tutor 1 were replies to the students' notes; Tutor 2 posted $63 \%$ as replies, but Tutor 3 posted only half (50\%) of her notes as replies; the rest were starting notes. In addition, Tutor 3 produced a considerable number of ideas herself in her group's discourse. It is observed that the students hardly replied to the notes of Tutor 1 and Tutor 2 at all, whereas they frequently replied to Tutor 3's notes measured as a proportion of the total number of her notes. The content of the tutors' scaffolding 
The tutors' notes $(\mathrm{N}=35)$ were analysed separately to investigate the content of their scaffolding. About $60 \%$ of the notes concentrated mostly on the contents of the inquiry. The following example is a reply note of Tutor 2 in the middle of the discourse thread of eight notes, in which the students wondered how the concept of intelligence could be formalized:

Problem 1999-04-07 12:15 Tutor 2: Do we need the concept of intelligence?

If the concept of intelligence is so vague, should we stop using it in scientific and formal discussions? Would it be better to use the sub-concepts that Pekka mentioned (memory, ability to learn, ability to concentrate etc.), which can be better defined and more accurately measured.

About $40 \%$ of the tutors' notes mostly handled issues of study methods, inquiry process and practices in the course. The following example is written by Tutor 1 as a reply to a male student's note, which included a request for other students in Group 1 to read an essay he had written earlier about human learning:

Metacomment 1999-03-29 12:44 Tutor 1: Writing the learning logs

I want to remind you that writing of your own learning logs is one of the requirements for course credit, and everybody has to remember to take part in it. Of course now (as in many other issues) you who are active and read notes, also get this note first, although it is not meant for you. Tell others about this reminder in your group. In this discussion all the participants have produced very interesting and meaningful notes, so continue this work that has started so well!

The contents of the tutors' notes were analysed in detail, using a scaffolding-oriented coding scheme. The tutors' notes were divided into 159 ideas, and each idea was classified into one of the four scaffolding categories.

Most ideas in the tutors' notes belonged to the category Ask explanation-seeking question (58 ideas, 37\%). About half of them were subordinate questions to the main research problems handled in the discourse ("Is it even possible to describe intelligence in some subdomain in an absolute way?"). In other questions, the tutors explicitly asked students to elaborate their explanations ("Can you explain more closely a basis for the presented idea that a group that consists of people with varying personalities and expertise works more efficiently?"), or to focus the inquiry ("Could you start by defining, what intelligence is?"). 
Ideas in the category Review and evaluate the discourse (39 ideas, 25\%) included almost as many neutral summaries of the discourse process ("Socially distributed cognition, team work, and intelligent activity are the concepts that have been used in the present discussion."), unmodified quotations from the students' notes, and positive and supportive evaluations of the process ("Good start for an important topic.").

The category Produce expert's explanation (36 ideas, 23\%) mostly included the tutors' own explanations for the inquiry questions ("Apparently, intelligence is also always relative, so that a person is intelligent in some domain when compared to other people."). About one third of the explanations were references to some scientific theory, source or concept.

In the scaffolding category Recommend study practices (26 ideas, 16\%), the tutors primarily gave rather general advice ("You have to ask the teacher about his evaluation"). Every tutor wrote one or two reminders about the importance of active participation in the FLEdiscourse, but it is difficult to say whether these general reminders were effective. A few ideas concerned technical advice about using FLE software. Only about one fourth of the ideas in this category were recommendations for sophisticated inquiry practices ("Next you could, for example, take into account the comments and define more specific working theory or problem that you first try to answer"). In the tutors' notes, there was no guidance that can be said to focus explicitly on advancing metacognitive awareness of the students concerning the inquiry strategies.

Table IV presents the frequencies and relative proportions of the categories of scaffolding in the three tutors' notes. According to $\chi 2$-test there was a significant difference between the tutors, $\chi 2(6, N=159)=18.32, \underline{p}<.01$. Cell-specific exact tests (Bergman \& ElKhouri, 1987) were carried out in order to examine whether the observed frequencies in each cell deviated from what could be expected by chance alone. 
One observes that the nature of scaffolding in the notes of Tutor 3, who was less experienced as a tutor and in the content area, differed most from the other tutors' postings. As can be seen from Table IV, Tutor 3 generated relatively more questions and fewer study recommendations and expert explanations compared to the other two tutors. The guidance of Tutor 1 was most evenly distributed into all four scaffolding categories.

\section{Progression of the inquiry discourse}

Below, the progression of the inquiry discourse, and the tutors' participation in it in each study group is briefly described, in order to evaluate the possible influence of the tutors' scaffolding on the students' engagement in inquiry.

In Group 1, the students had four questions to work on. The group was rather small, only four students. The discourse started in a general forum (including 6 notes) with some considerations of the working practices. Tutor 1 wrote a note including advice to choose a research problem and continue the discourse under that questions' discourse forum, and the students acted accordingly. In the discourse of the first question ( 9 notes), one student posted a note proposing two subordinate questions, but other students reacted only after the tutor asked others to share their opinions and knowledge that had emerged during the lectures. This concrete advice appears to have affected the discourse: In the succeeding notes, the students wrote elaborate reflections about some theories related to the question under study. The tutor wrote one additional note to the end of the thread, including her own explanations and a reference to a theory.

The discourse patterns of the second question (18 notes in all), and the third question (19 notes) resembled one another. The students started the discourse by elaborating the question further and referring to some theories. The tutor participated in both discourses twice by producing some subordinate questions or new theoretical viewpoints. Her notes were commented on by the students, but the notes did not significantly direct the discourse. The inquiry did not seem to progress deeper; the students wrote about their own experiences and 
explanations, or reviewed some theories rather casually. The fourth question (5 notes) generated a short discourse thread, in which the students reviewed some theories discussed in the lecture, and their own experiences related to the issue. The tutor did not participate in that discourse, and it was not very focused on the original question.

The discourse of Group 1 appears to have been especially characterised by rich referencing to theories discussed in lectures or in other knowledge sources, but not so much by progressive inquiry. Possibly the tutor's concrete advice to review theories discussed in the lectures, on the one hand, and her own example to present and review theories, on the other hand, promoted such a discourse pattern.

In Group 2, seven students had three questions to work on. The discourse started in a general forum (14 notes in all) with the discussion of the working practices in FLE, and some students' tentative elaboration of the research questions. Tutor 2 wrote several notes, in which she concretely advised the students to specify their research question and continue the discourse under the forum for the chosen problem, and the students acted accordingly. At the end of the course, some students and the tutor discussed the requirements for course credit; the students appear to have been insecure about the evaluation criteria.

The discourses of the first question (20 notes) and the second question (30 notes) started with a few student notes elaborating the issue and presenting several subordinate questions. The tutor participated in both discourses by writing notes in which she presented her own ideas about the issue or reflected on the preceding discourse, and suggested going in a certain theoretical direction. This precise content-related guidance appears to have focused the subsequent discourse, and the students produced many elaborate explanations related to the new line. The discourse was sustained in the sense that the students frequently referred to each other's ideas although all the notes were not explicitly in the same discourse thread. The discourse of the third question (24 notes) included many successive notes, in which the students quoted previous notes and added some new viewpoints to the discourse, but there were not 
many references to knowledge sources or deepening of the explanations. The tutor contributed to the discourse twice, at long intervals, by sending a note reminding the students about the original question, and a note asking whether they had gotten any new ideas from course materials. Seemingly, such general guidance did not strongly influence the discourse.

Specific to the discourse of Group 2 appears to have been sustained and occasionally deepening — but not very theoretical—inquiry, which was probably fostered by the tutor's metalevel reflections and content-related focusing. Such notes, in which the tutor suggested subordinate questions based on the preceding discourse, appear to have focused the discourse.

Group 3 had six participating students and four questions to work on. There was no general discussion about the working practices. In the discourse of the first question (42 notes), one student especially was very active in elaborating the question further to more specific questions and themes. After about two weeks, Tutor 3 posted a note in which she reflected the preceding discourse, recommended that the students define some concepts, and encouraged all students to participate. This concrete advice generated a discourse of rather short notes, including concept definitions, questions, and ideas of the issue under study. Later on, the tutor suggested some new ideas and questions, and encouraged the students to think about their opinions of them; these notes generated some further discussion.

In the early state of the discourse of the second question (25 notes in all), Tutor 3 posted two notes concretely requesting the students to specify their explanations; the request was followed by some replies. Later on, the tutor asked the students to define a main question for the discourse. One student reacted by writing three questions to work on, and other students continued with notes including their own elaborations of the questions, but not any theory-based considerations. The tutor participated in the subsequent discourse with three notes, suggesting some new ideas and questions about the issue. The third question (20 notes) was examined in one long discourse thread, in which the students presented several ideas, own explanations and subordinate questions to the original question without much reference to scientific theories or 
knowledge sources. Tutor 3 posted one note to the discourse, suggesting a new theoretical viewpoint and some further questions, which were discussed in some student notes. The fourth question (8 notes) generated a short discourse in which the tutor did not participate.

The discourse of Group 3 can be characterised as a dialogic and idea-rich discussion, but not very deepening or focused on theory building. It appears likely that the tutor's concrete direction for the students to actively write about their personal opinions, explanations and questions, on the one hand, and her own example in presenting several new ideas and questions in her notes, on the other hand, influenced the divergent style of the discourse.

\section{Discussion}

The term 'scaffolding' implies that the guidance given to learners should be directed, especially, to issues that are beyond their reach without guidance. In the investigated university course, the goal was to elicit deepening, sustained, question-driven inquiry in groups of learners. The students were offered support for this challenge by explaining the model of progressive inquiry to illustrate the central strategies of inquiry, and furnishing them with collaborative technology (FLE) including built-in inquiry scaffolds. In addition, a tutor participated in each study group's work in FLE to provide human scaffolding during the process.

The special focus in the present study was on the tutors' contribution to the students' computer-mediated inquiry discourse. There is evidence that the combination of various analysis methods used in the study provided new insights into the challenges of scaffolding collaborative inquiry learning. The results of the descriptive statistics gave one view of the inquiry activity, but the students' level of activity in replying, or length of discourse threads, did not tell much about the real progression of inquiry. More exploratory analysis of the discourse progression enabled us to examine the possible effects of the tutors' process-level scaffolding on the students' engagement in inquiry. Further, the qualitative content analysis of the tutors' postings provided systematic data for evaluating and comparing the three tutors' contributions. 
According to the results, the tutors were not the most active participants in their groups: There is evidence that they managed to transfer responsibility for the discourse to the students. Also the tutors' frequent use of the inquiry scaffold, Metacomment, indicated that they tried to act as process organisers and facilitators in the inquiry. In any case, the tutors produced many content-related problems and explanations themselves, and, hence, appear to have acted also as content experts (Tutors 1 and 2) or co-inquirers (Tutor 3) in the discourse.

Most of the explicit process guidance in the tutors' postings concentrated on rather practical issues, such as using information sources or organising the work in FLE course. The guidance did not, on the present evidence, draw the students' attention to higher-order metacognitive strategies. The tutors did not, for example, explicitly advise the students critically to evaluate the produced ideas, to sum up the discourse, or to build on each other's ideas. On the contrary, the tutors themselves wrote elaborate evaluations and reviews of the process, which resembled a rather traditional way of conducting the task of evaluation as a teacher's responsibility. In research on pre-service teachers' telementoring practices, Hewitt, Reeve, Abeygunawardena, and Vaillancourt (2002) obtained similar results: The teachers manifested a quite traditional instructional teacher-led style. Their notes contained a great deal of encouragement, and questions and statements relating to the content area, but there were a relatively small number of instances of process guidance to help students manage the inquiry themselves.

The influence of the tutors' scaffolding on the students' engagement in inquiry

The impression, obtained from the exploratory analysis of the discourse, was that the type and frequency of the tutors' guidance had an effect on the style of the inquiry discourse in each group. The discourse in the three groups concentrated somewhat more on theory reviewing, focusing of the inquiry, or generating of divergent ideas, respectively, depending on what kind of advice and expert model the tutor of the group offered. The tutor's encouragement for presenting new ideas and questions activated the students' dialogic interaction, but it did not 
necessarily guarantee that the goal of deepening inquiry process was met. The scaffolding that appears to have promoted deepening discourse, may be characterised as explicitly built on the students' preceding discourse and, accordingly, as providing a content-specific and well-timed expert recommendation to refocus the inquiry. Those discourse threads, in which the tutors did not participate at all, were not very sustained and deepening.

In general, the analysis of the discourse threads indicates that clear, specific advice was more influential than vague and more general advice, whether it related to content-specific issues, concrete actions and study practices, or cognitive strategies. Naturally, it is relatively simple to give easy-to-follow advice about practical issues; it is more challenging to give advice that supports the development of higher-order metacognitive strategies. Perhaps one difficulty for scaffolding students' metacognitive advancement in the investigated course, as in the setting studied by Hewitt and his colleagues (2002), arose from the lack of face-to-face interaction. It is not easy to explain and advise regarding complex issues by simply writing notes to a discourse forum. We suggest that it may not be possible to provide all needed scaffolding through computer-mediated communication. This position should be taken into account in organising the educational settings using collaborative technology.

The interrelation of the process-level scaffolding and the overall organisation of activity

The students' overall level of activity in participating in the computer-mediated discourse in the investigated course was not very high, conforming to similar results reported in other studies (e.g., Hara, Bonk \& Angeli, 2000). All the tutors sent some activating requests to their group's discourse, but apparently the influence on the students' activity level in this way was limited. Probably more important in promoting the students' commitment to the inquiry process, was the overall organisation of the activity. Students tend to direct their efforts into those issues for which they are rewarded; hence the entire learning context should be organised so that the criteria and structures for the activity foster engagement in active and extensive process of inquiry. 
As Tabak (2004) proposed, the various scaffolding components in a complex learning environment should be in synergy with each other, addressing the same learning goals and reinforcing one another to produce stronger support. In the investigated course, the students' inquiry process was initially supported by a guided question-creation process, but perhaps the consequent activity was too loosely organised, relying on the students' self-regulation. For example, the groups were not formed systematically; the students and tutors did not have faceto-face meetings; the FLE discourse and the lectures were only loosely related to each other; and there were no clear, explicitly stated requirements for course credit or inquiry outcomes. Hence our impression is that the task organisation level, tool level, and process level scaffolding did not fully complement one another.

In progressive inquiry, the aim is to encourage students themselves to define research questions and theoretical explanations, and direct their collaborative inquiry efforts. If the way of working is new for the students, it may be necessary for a tutor to give rather explicit advice and actively model the desirable strategies at the beginning of the process. Yet gradually the students should learn to master the challenging cognitive and metacognitive strategies themselves. Probably such advancement is not realistic to expect within one, short-term university course, but requires scaffolded practice of metacognitive inquiry strategies throughout one's studies. That proper amount of practice requires broad, coordinated changes in curriculum design and learning culture (Lin, 2001; Muukkonen et al., 2004). Varying expertise of the tutors

The comparison of the three tutors revealed intriguing differences in their ways of contributing to the inquiry. The two more experienced tutors mainly replied to the students' notes. The third, less-experienced tutor, instead, produced many new starting notes herself, and the proportion of problem statements in her notes was much greater than in the notes of the other tutors. Her notes received plentiful replies from the students. The process analysis indicated that the efforts of the more-experienced two tutors were more explicitly directed to 
deepen the inquiry: Tutor 1 tried to encourage the students to use knowledge sources and theoretical explanations, and Tutor 2 attempted to deepen the discourse to more focused questions. The less-experienced Tutor 3 appears to have acted more spontaneously by herself suggesting many new ideas and subordinate questions.

The activity patterns of the three tutors can be examined using the categories proposed by Bereiter and Scardamalia (1987; Scardamalia, 2002). They described the teacher's role, in the context of knowledge building pedagogy, by defining teacher models A, B, and C. Teacher A's focus is on organising students' activities without taking cognitive responsibility for their learning. Teacher B, in contrast, directly assumes the cognitive responsibility by asking questions and explaining the issues being investigated. Teacher B is so much involved in inquiry process that he or she may be regarded as a co-inquirer rather than just a coach of the students. Teacher $\mathrm{C}$, in turn, engages in an intensive effort to get the students to pose questions themselves as well as pursue their own explanations. Teacher $\mathrm{C}$ does basically everything that teacher B does but tries to insure that the students come to do it themselves.

Tutor 3's practice can be interpreted as resembling the Teacher B model; she acted as an active participant and an initiator of new wonderment in the inquiry process. Arguably, the more experienced two tutors represented an intermediate position between the Teacher B model and the Teacher $\mathrm{C}$ model. They appear to have sought to change their role from participating actively to promoting the students' assumption of responsibility for the inquiry. They did not, however, draw the students' attention to higher-order metacognitive strategies; their process guidance mainly focused on concrete inquiry practices - such as what discourse forum the students should use - or they themselves suggested new theories and directions to the inquiry. It is, as Scardamalia (2002) stated, a challenging learning accomplishment for educators to move from approving the Teacher $\mathrm{C}$ mode to the point of actually practicing it. In addition to theoretical knowledge of advanced pedagogical approaches, tutors would benefit from reflecting critically on their scaffolding practices. 


\section{Conclusion}

Successful scaffolding should include all elements that were present in the tutors' separate practices: promotion of idea-rich dialogue, exploitation of knowledge sources and scientific theories, and fostering the deepening of inquiry. Such tutoring requires various social, pedagogical and technical competencies, and robust subject-domain expertise. One sophisticated solution is that the scaffolding responsibility for each student group is undertaken jointly by several experts; e.g., an instructor and tutors with varying expertise. One benefit of collaborative technology in such an arrangement is that the scaffolding processes can be easily shared, then evaluated afterwards.

\section{Acknowledgements}

The authors thank all persons who have given valuable comments to make the article better, especially Lasse Lipponen, Liisa Ilomäki, Jiri Lallimo, Marjaana Veermans, and Hal White. We also wish to thank two anonymous reviewers for their comments on an earlier version of this article. The first author was supported by an individual grant from The Finnish Cultural Foundation in the years 2000-2002.

\section{References}

BEREITER, C. \& SCARDAMALIA, M. (1987) An attainable version of high literacy: Approaches to teaching higher-order skills in reading and writing, Curriculum Inquiry, 17, pp. 9-30.

BERGMAN, L. R. \& EL-KHOURI, B. (1987) Exacon: A Fortran 77 program for the exact analysis of single cells in a contingency table, Educational and Psychological Measurement, 47, pp. 155-161.

BIELACZYC, K. (2001) Designing Social Infrastructure: The Challenge of Building ComputerSupported Learning Communities, in: P. Dillenbourg, A. Eurelings \& K. Hakkarainen (Eds) European Perspectives on Computer-Supported Collaborative Learning (Maastricht, Maastricht McLuhan Institute). 
BROWN, A. L., ASH, D., RUTHERFORD, M., NAKAGAWA, K., GORDON, A. \& CAMPIONE, J. (1993) Distributed expertise in the classroom, in: G. SALOMON (Ed) Distributed cognitions: Psychological and educational considerations (Cambridge, Cambridge University Press).

CHI, M.T.H. (1997) Quantifying qualitative analyses of verbal data: A practical guide, Journal of the Learning Sciences, 6, pp. 271-315.

DILlENBOURG, P. (Ed) (1999) Collaborative learning: Cognitive and computational approaches (Amsterdam, Elsevier).

DYSTHE, O. (2000) The learning potential of a web-mediated discussion in a university course, Studies in Higher Education, 27, pp. 339-352.

EDELSON, D.C., GORDIN, D.N. \& PEA, R.D. (1999) Addressing the challenges of inquirybased learning through technology and curriculum design. Journal of the Learning Sciences, 8, pp. 391-450.

GUZDIAL, M. (1997) Information ecology of collaborations in educational settings: Influence of tool, in: R. HALL, N. MIYAKE \& N. ENYEDY (Eds) Proceedings of CSCL '97: The Second International Conference on Computer Support for Collaborative Learning (Mahwah, Erlbaum).

HAKKARAINEN, K. (2003) Emergence of progressive inquiry culture in computer-supported collaborative learning, Learning Environments Research, 6, pp. 199-220.

HAKKARAINEN, K. \& SINTONEN, M. (2002) Interrogative Model of Inquiry and ComputerSupported Collaborative Learning, Science \& Education, 11, pp. 24-43.

HARA, N., BONK, C.J. \& ANGELI, C. (2000) Content analysis of online discussion in an applied educational psychology course, Instructional Science, 28, pp. 115-152.

HEWITT, J., REEVE, R., ABEYGUNAWARDENA, H. \& VAILLANCOURT, B. D. (2002) Pre-service teachers as telementors: exploring the links between theory and practice, Journal of Information Technology for Teacher Education, 11, pp. 7-22. 
HINTIKKA, J. (1982) A dialogical model of teaching, Synthese, 51, pp. 39-59.

HOGAN, K. \& PRESSLEY, M. (1997) Scaffolding scientific competencies within classroom communities of inquiry, in: K. HOGAN \& M. PRESSLEY (Eds) Scaffolding student learning: Instructional approaches and issues (Cambridge, Brookline Books).

KOLODNER, J.L. (2001) A note from the editor, The Journal of the Learning Sciences, 10, pp. $1-4$.

KOSCHMANN, T., HALL, R. \& MIYAKE, N. (Eds) (2001) CSCL2: Carrying forward the conversation (Mahwah, Erlbaum).

LAKKALA, M., ILOMÄKI, L., LALLIMO, J. \& HAKKARAINEN, K. (2002) Virtual communication in middle school students' and teachers' inquiry, in: G. STAHL (Ed) Computer Support for Collaborative Learning: Foundations for a CSCL community (Hillsdale, Erlbaum).

LAHTI, H., SEITAMAA-HAKKARAINEN, P. \& HAKKARAINEN, K. (2003) Piloting participatory designing within a collaborative design environment, Journal of Interactive Learning Research, 14, pp. 185-207.

LEHTINEN, E. (2003) Computer supported collaborative learning: An approach to powerful learning environments, in: E. DE CORTE, L. VERSCHAFFEL, N. ENTWISTLE \& J. VAN MERRIËBOER (Eds) Unraveling basic components and dimensions of powerful learning environments (New York, Pergamon).

LEPPER, M., DRAKE, M. \& O’DONNELL-JOHNSON, T. (1997) Scaffolding techniques of expert human tutors, in: K. HOGAN \& M. PRESSLEY (Eds), Scaffolding student learning: Instructional approaches and issues (Cambridge, Brookline Books).

LEVIN, B. (1999) The role of the facilitator in case discussions, in: M. LUNDBERG, B. LEVIN \& H. HARRINGTON (Eds) Who learns what from cases and how? The research base for teaching and learning with cases (Hillsdale, Erlbaum). 
LIGORIO, M.B., TALAMO, A. \& R.J. SIMONS (2002) Synchronic tutoring of a virtual community, Mentoring \& Tutoring: Partnership in Learning, 10, pp. 137-152.

LIN, X. (2001) Designing Metacognitive Activities, Educational Technology Research \& Development, 49, pp. 23-40.

MCGRAW, K.O. \& WONG, S.P. (1996) Forming inferences about some intraclass correlation coefficients, Psychological Methods, 1, pp. 30-46.

MERCER, N. \& FISCHER, E. (1993) How do teachers help children to learn? An analysis of teachers' interventions in computer-based activities, Learning and Instruction, 2, pp. $339-355$.

MUUKKONEN, H., HAKKARAINEN, K. \& LAKKALA, M. (1999) Collaborative technology for facilitating progressive inquiry: Future Learning Environment Tools, in: C.M. HOADLEY and J. ROSCHELLE (Eds) Proceedings of the Computer Support for Collaborative Learning 1999 Conference (Mahwah, Erlbaum).

MUUKKONEN, H., HAKKARAINEN, K. \& LAKKALA, M. (2004) Computer-mediated progressive inquiry in higher education, in: T. S. ROBERTS (Ed) Online collaborative learning: Theory and practice (Hershey, Information Science Publishing).

MUUKKONEN, H., LAKKALA, M. \& HAKKARAINEN, K. (2001) Characteristics of university students' inquiry in individual and computer-supported collaborative study process, in: P. DILLENBOURG, A. EURELINGS \& K. HAKKARAINEN (Eds), European perspectives on computer-supported collaborative learning (Maastricht, Maastricht McLuhan Institute).

PUNTAMBEKAR, S. \& KOLODNER, J.L. (1998) Distributed scaffolding: Helping students learn in a learning by design environment, in: A.S. Bruckman, M. Guzdial, J.L. Kolodner \& A. Ram (Eds), Proceedings of the International Conference of the Learning Sciences 1998 (Charlottesville, AACE). 
REISER, B. (2004) Scaffolding Complex Learning: The Mechanisms of Structuring and Problematizing Student Work, Journal of the Learning Sciences, 13, pp. 273-304.

ROURKE, L., GARRISON, D.R. \& ARCHER, W. (2001) Assessing teacher presence in a computer conferencing context, Journal of Asynchronous Learning Networks, 5, pp. 117.

RUSSELL, A. \& PERRIS, K. (2003) Telementoring in community nursing: a shift from dyadic to communal models of learning and professional development, Mentoring \& Tutoring: Partnership in Learning, 11, pp. 227-239.

SCARDAMALIA, M. (2002) Collective cognitive responsibility for the advancement of knowledge, in: B. SMITH (Ed) Liberal education in the knowledge society (Chicago, Open Court).

SCARDAMALIA, M. \& BEREITER, C. (1994) Computer support for knowledge-building communities, The Journal of the Learning Sciences, 3, pp. 265-283.

STASSER, G. (1999) The uncertain role of unshared information in collective choice, in: L.L. THOMPSON, J. M. LEVINE \& D. M. MESSICK (Eds) Shared cognition in organizations: The management of knowledge (Mahwah, Erlbaum).

TABAK, I. (2004) Synergy: A Complement to Emerging Patterns of Distributed Scaffolding, The Journal of the Learning Sciences, 13, pp. 305-335.

WELLS, G. (2000) Dialogic inquiry in education: Building on the Legacy of Vygotsky, in: C.D. Lee \& P. Smagorinsky (Eds) Vygotskian perspectives on literacy research. Constructing meaning through collaborative inquiry (Cambridge, Campridge University Press).

WOOD, D., BRUNER, J.S. \& ROSS, G. (1976) The role of tutoring in problem solving, Journal of Child Psychology and Psychiatry, 17, pp. 89-100.

WOOD, D. \& WOOD, H. (1996) Vygotsky, tutoring and learning, Oxford Review of Education, 22, pp. 5-17. 
Table I. Summary of the database material used in the study

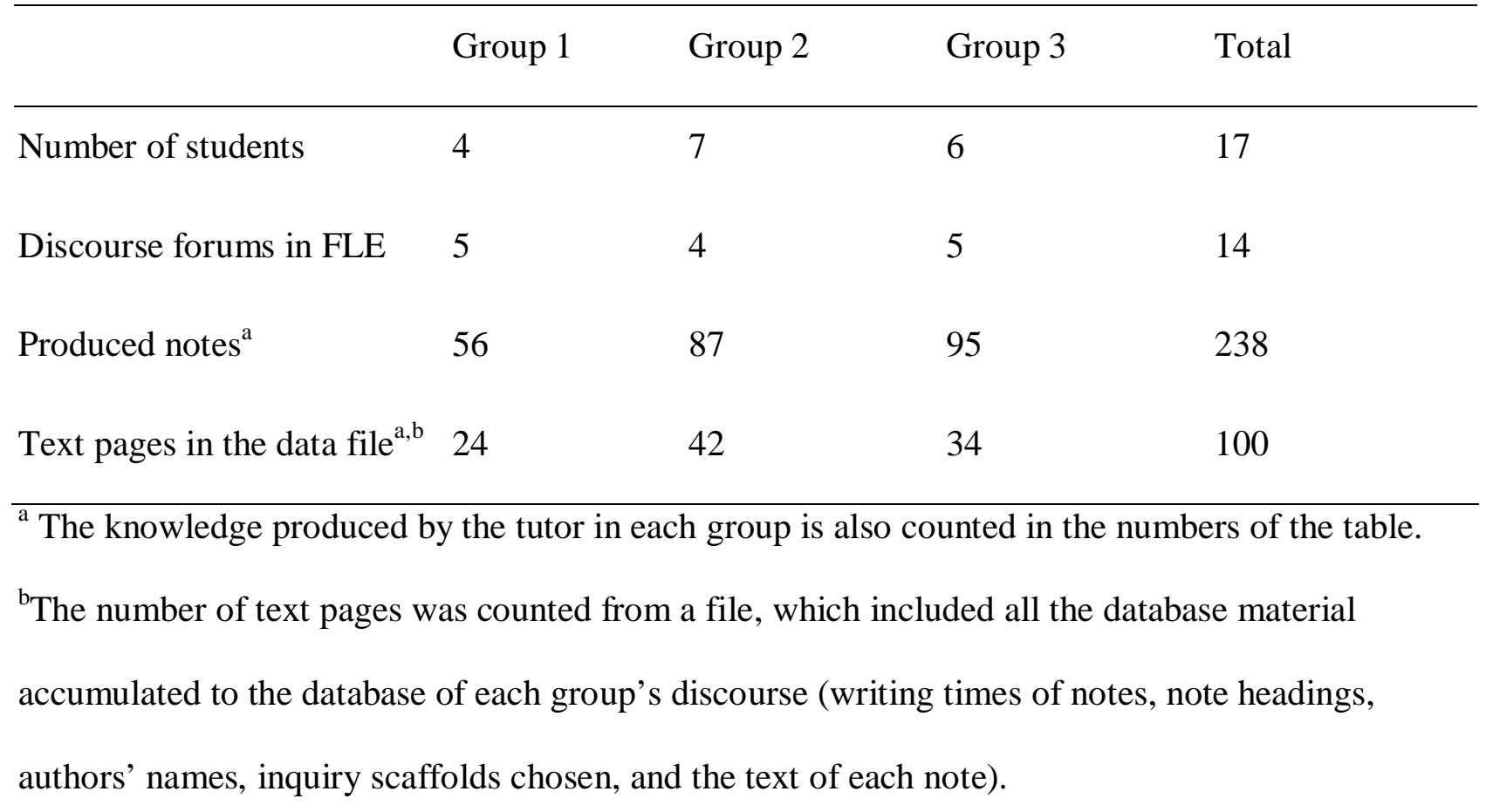


Table II. An example of the first four notes in a discourse thread of six notes. The boundaries of the segments used in the content analysis are marked by two slashes (//). The text is translated from Finnish.

Problem 1999-02-24 15:12 Susan T.: A goal or a value as such?

How much does it influence study success, whether a student works only because of some goal after studies, a reward earned from the studies like a good job, or does a student see the learning process interesting and valuable in itself? //

Comment 1999-02-24 18:18 John P: The source of motivation?

I think that it doesn't matter what is the source of motivation but how strong it is. If you want to learn something or you need to learn something, you usually learn it. // Though, the motivation that is based on your own desire feels more enjoyable. // I usually feel it depressing, if I have to learn forcibly - this might, of course, relate to the learning result at long sight. //

Metacomment 1999-02-26 8:45 Tutor 3: a few questions

[A quote of the previous note] // Tutor's comment: It is good that you have participated actively in the discussion about the importance of motivation in learning. // Can you explain, in more detail, why highly motivated person gain better learning results than poorly motivated person? // Further: You discuss various sources of motivation, can you specify? // What are the "sources of motivation" and is one "source" more effective than some other? // Why? //

Metacomment 1999-02-28 20:10 John P.: Motivation
[A quote of the previous note] // [Definition of words motivation and motive
quoted from a Finnish book about psychological words] // Based on the
preceding (non-scientific summary): If a person is motivated to learn
something, or he has a goal to learn something, he uses more resources in the
learning than when he is not motivated. // In motivation the motives direct
behaviour. Motives are based on needs. // According to the need hierarchy you
first have to get food (study grants -> pizza), feel yourself secure (student
apartment), belong to a community/family (student association/intimate
relations), feel self-respect (access to university) before you start to actualise
your self by reading to an exam. // Though, if you don't read you don't get
study grants ... // Anyhow, it may be very subjective, which motive is the
most effective.


Table III. Characteristics of the threads, posted notes, and replies, by study group.

\begin{tabular}{|c|c|c|c|}
\hline & Group 1 & Group 2 & Group 3 \\
\hline & (4 students) & (7 students) & (6 students) \\
\hline \multicolumn{4}{|l|}{ Discourse threads } \\
\hline No. threads & 14 & 17 & 12 \\
\hline Length, Mean (Min/Max) & $3.3(2 / 6)$ & $4.1(2 / 9)$ & $7.1(2 / 20)$ \\
\hline \multicolumn{4}{|l|}{ Students' notes } \\
\hline No. notes, Mean (Min/Max) & $11.8(3 / 20)$ & $10.1(3 / 19)$ & $14.2(3 / 33)$ \\
\hline No. ideas in notes, Mean & 7.1 & 8.6 & 4.8 \\
\hline Sent replies, Mean & 5.3 & 5.3 & 8.8 \\
\hline Received replies, Mean & 6.8 & 7.0 & 8.2 \\
\hline \multicolumn{4}{|l|}{ Tutors' notes } \\
\hline No. notes & 9 & 16 & 10 \\
\hline No. ideas in notes, Mean & 4.4 & 3.5 & 6.3 \\
\hline Proportion of all ideas & $11 \%$ & $8 \%$ & $13 \%$ \\
\hline Sent replies & 8 & 10 & 5 \\
\hline Received replies & 2 & 4 & 9 \\
\hline
\end{tabular}


Table IV. Proportions of the elements of scaffolding in the tutors' notes based on the categorisation of ideas

\begin{tabular}{|c|c|c|c|c|c|c|c|c|c|}
\hline \multirow[b]{2}{*}{ Category of scaffolding } & \multicolumn{2}{|c|}{ Tutor 1} & \multicolumn{2}{|c|}{ Tutor 2} & \multicolumn{3}{|c|}{ Tutor 3} & \multicolumn{2}{|c|}{ Total } \\
\hline & $\underline{\mathrm{f}}$ & $\%$ & $\underline{\mathrm{f}}$ & $\%$ & $\underline{\mathrm{f}}$ & & $\%$ & $\underline{\mathrm{f}}$ & $\%$ \\
\hline $\begin{array}{l}\text { Ask explanation-seeking } \\
\text { question }\end{array}$ & $9^{*}$ & 22.5 & $14^{*}$ & 25.0 & 35 & $\dagger \dagger$ & 55.6 & 58 & 36.5 \\
\hline $\begin{array}{l}\text { Produce expert's } \\
\text { explanation }\end{array}$ & 10 & 25.0 & 17 & 30.3 & 9 & * & 14.3 & 36 & 22.6 \\
\hline $\begin{array}{l}\text { Review and evaluate the } \\
\text { discourse }\end{array}$ & 11 & 27.5 & 15 & 26.8 & 13 & & 20.6 & 39 & 24.5 \\
\hline $\begin{array}{l}\text { Recommend study } \\
\text { practices }\end{array}$ & 10 & 25.0 & 10 & 17.9 & 6 & $*$ & 9.5 & 26 & 16.4 \\
\hline Total & 40 & 100.0 & 56 & 100.0 & 63 & & 100.0 & 159 & 100.0 \\
\hline
\end{tabular}

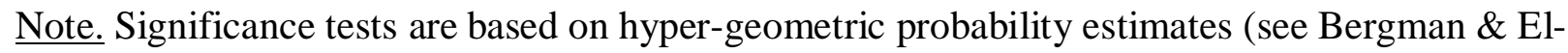
Khouri, 1987).

* Observed frequency smaller than expected by chance alone $(\mathrm{p}<.05)$.

${ }^{\dagger \dagger}$ Observed frequency larger than expected by chance alone $(p<.001)$. 